\title{
O biocombustível no Brasil: potencialidades da cultura do Crambe abyssinica para produção de biodiesel
}

\author{
Biofuels in Brazil: potentialities of Crambe abyssinica culture for biodiesel production \\ Biocombustibles en Brasil: potencialidades del cultivo de Crambe abyssinica para la producción de \\ biodiesel
}

Recebido: 03/04/2021 | Revisado: 11/04/2021 | Aceito: 16/04/2021 | Publicado: 30/04/2021

\author{
Isabela Reis Queiroz \\ ORCID: https://orcid.org/0000-0002-4485-4505 \\ Universidade Federal dos Vales do Jequitinhonha e Mucuri, Brasil \\ E-mail: belaqueirozz@gmail.com \\ Alexandre Sylvio Vieira da Costa \\ ORCID: https://orcid.org/0000-0001-7251-7816 \\ Universidade Federal dos Vales do Jequitinhonha e Mucuri, Brasil \\ E-mail: alexandre.costa@ufvjm.edu.br \\ Ivana Carneiro Almeida \\ ORCID: https://orcid.org/0000-0001-6069-919X \\ Universidade Federal dos Vales do Jequitinhonha e Mucuri, Brasil \\ E-mail: ivana.carneiro@ufvjm.edu.br \\ Geórgia Fernandes Barros \\ ORCID: https://orcid.org/0000-0003-1362-9548 \\ Universidade Federal dos Vales do Jequitinhonha e Mucuri, Brasil \\ E-mail: georgia.barros@ufvjm.edu.br \\ Wederson Marcos Alves \\ ORCID: https://orcid.org/0000-0002-1105-1300 \\ Universidade Federal dos Vales do Jequitinhonha e Mucuri, Brasil \\ E-mail: wederson.alves@ufvjm.edu.br \\ Marcio Coutinho de Souza \\ ORCID: https://orcid.org/0000-0002-4238-1572 \\ Universidade Federal dos Vales do Jequitinhonha e Mucuri, Brasil \\ E-mail: marcio.souza@ufvjm.edu.br \\ Mauro Lúcio Franco \\ ORCID: https://orcid.org/0000-0003-2114-4399 \\ Universidade Federal dos Vales do Jequitinhonha e Mucuri, Brasil \\ E-mail:ml.franco@ufvjm.edu.br \\ Raquel de Souza Pompermayer \\ ORCID: https://orcid.org/0000-0002-2455-3027 \\ Universidade Federal dos Vales do Jequitinhonha e Mucuri, Brasil \\ E-mail: raquel.pomper@ufvjm.edu.br \\ Artemiza Oliveira Souza \\ ORCID: https://orcid.org/0000-0002-1187-4403 \\ Universidade Federal dos Vales do Jequitinhonha e Mucuri, Brasil \\ E-mail: artemiza.oliveira@ufvjm.edu.br \\ Allan Castro Ferreira \\ ORCID: https://orcid.org/0000-0002-2779-247X \\ Universidade Federal dos Vales do Jequitinhonha e Mucuri, Brasil \\ E-mail: allan.ferreira@ufvjm.edu.br
}

\begin{abstract}
Resumo
Este artigo teve como objetivo realizar um levantamento das principais características da oleaginosa Crambe abyssinica, abordando desde a ecologia e morfologia da espécie até as condições de cultivo e produção de biodiesel. Realizou-se um estudo qualitativo por meio de revisão de literatura sobre a espécie e a produção de biodiesel, analisando materiais bibliográficos produzidos entre os anos de 1970 e 2019 indexados em bases de dados nacionais e internacionais. Os resultados demonstraram que devido ao ciclo curto e a alta produção de triglicerídeos nas sementes, a espécie, apresenta elevado potencial para a produção de biodiesel. Somado a isso, a cultura demonstra características interessantes para o produtor, como baixo custo de produção, tolerância às variações de temperatura e estresse hídrico, podendo ser utilizada em rotação de culturas e como planta de cobertura do solo. Com a revisão bibliográfica foi possível descrever o perfil cromatográfico do óleo de Crambe abyssinica além de verificar a estimativa do
\end{abstract}


esgotamento de combustíveis fósseis para as próximas décadas, associado ao aumento da demanda energética no planeta. A utilização do biodiesel está relacionada a fatores ambientais por possibilitar a diminuição de emissão de gases tóxicos e a reciclagem de nutrientes e a fatores sociais e econômicos por beneficiar produtores rurais, conforme demonstra vasta literatura. Diante destas considerações, verificou-se a viabilidade do cultivo de Crambe abissynica para obtenção de matéria prima e a produção de biodiesel.

Palavras-chave: Crambe; Biocombustíveis; Sustentabilidade.

\begin{abstract}
This article aimed to carry out a survey of the main characteristics of the oilseed Crambe abyssinica, covering from the ecology and morphology of the species to the conditions of cultivation and production of biodiesel. A qualitative study was performed through a literature review on the species and the production of biodiesel, analyzing bibliographic materials produced between the years 1970 and 2019 indexed in national and international databases. The results showed that due to the short cycle and the high production of triglycerides in the seeds, the species has a high potential for the production of biodiesel. In addition, the crop showed interesting characteristics for the producer, such as low production cost, tolerance to temperature variations and water stress, which can be used in crop rotation and as a ground cover plant. From the bibliographic review it was possible to describe the chromatographic profile of Crambe abyssinica oil and in addition verify the estimate of fossil fuel depletion for the next decades, associated with the increase in energy demand on the planet. The use of biodiesel is related to environmental factors insofar as it allows the reduction of toxic gas emissions and nutrients recycling and related to social and economic factors as it benefits rural producers, as demonstrated by the vast literature. In view of these considerations, the viability of Crambe abissynica cultivation to obtain raw material and the production of biodiesel was verified.
\end{abstract}

Keywords: Crambe; Biofuels; Sustainability.

\title{
Resumen
}

Este artículo tuvo como objetivo realizar un relevamiento de las principales características de la oleaginosa Crambe abyssinica, abarcando desde la ecología y morfología de la especie hasta las condiciones de cultivo y producción de biodiesel. Se realizó un estudio cualitativo a través de una revisión de la literatura sobre la especie y la producción de biodiesel, analizando materiales bibliográficos producidos entre los años 1970 y 2019 indexados en bases de datos nacionales e internacionales. Los resultados mostraron que debido al ciclo corto y la alta producción de triglicéridos en las semillas, la especie tiene un alto potencial para la producción de biodiesel. Además, el cultivo presenta características interesantes para el productor, como bajo costo de producción, tolerancia a variaciones de temperatura y estrés hídrico, que puede ser utilizado en rotación de cultivos y como planta de cobertura del suelo. Con la revisión bibliográfica se logró describir el perfil cromatográfico del aceite de Crambe abyssinica además de verificar la estimación del agotamiento de los combustibles fósiles para las próximas décadas, asociado al aumento de la demanda energética del planeta. El uso de biodiesel está relacionado con factores ambientales, ya que permite la reducción de las emisiones de gases tóxicos y el reciclaje de nutrientes y con factores sociales y económicos, ya que beneficia a los productores rurales, como lo demuestra la vasta literatura. Teniendo en cuenta estas consideraciones, se verificó la viabilidad del cultivo de Crambe abissynica para la obtención de materia prima y la producción de biodiesel.

Palabras clave: Crambe; Biocombustibles; Sostenibilidad.

\section{Introdução}

O Crambe (Crambe abyssinica Hochst), espécie vegetal da família das crucíferas, vem se destacando em terras brasileiras por apresentar características como: rusticidade, precocidade, tolerância ao déficit hídrico e ciclo de produção reduzido, cerca de 90 dias. Esta planta apresenta-se como uma alternativa importante no manejo da rotação de culturas, podendo ser cultivada no período da safrinha, em grande parte do cerrado brasileiro, não competindo com as culturas principais e as alimentares. Outra vantagem em relação a produção desta oleaginosa é seu cultivo totalmente mecanizado com equipamentos utilizados em outras culturas, como na soja (Roscoe \& Delmontes, 2008).

Por apresentar até $40 \%$ de óleo em suas sementes e ser cultivado no período da safrinha, o Crambe representa uma promissora opção para a produção de biodiesel tendo em vista que os óleos utilizados para este fim são advindos de culturas anuais, principalmente de ciclo primavera/verão, sem muitas alternativas para o período de outono/inverno que permitam dar continuidade à produção (Bispo et al., 2010). O biodiesel (produto obtido através do processo de transesterificação de óleos e gorduras de origem vegetal ou animal) é considerado um biocombustível por ser produzido a partir de fontes renováveis e biodegradáveis. Os biocombustíveis emitem compostos poluentes em menor quantidade que os combustíveis fósseis no 
processo de combustão dos motores e sua cadeia de produção é mais limpa (Knothe et al., 2007; Petrobras, 2018).

Quando comparado aos combustíveis fósseis, os biocombustíveis emitem menos poluentes durante o processo de combustão e sua síntese consiste em um processo mais limpo. Assim, configura-se o biodiesel como um biocombustível bastante promissor, pois se trata de uma alternativa para substituição do óleo diesel, sendo que sua queima pode emitir em média $48 \%$ menos monóxido de carbono, $47 \%$ menos material particulado e $67 \%$ menos hidrocarbonetos, quando comparada a queima do diesel de petróleo (ANP, 2015, apud Galina \& et al., 2020, p. 1).

O uso do biodiesel no Brasil proporciona o desenvolvimento de uma fonte energética sustentável sob o viés ambiental, econômico e social, por tornar o país menos dependente do petróleo importado, aumentar a oferta de empregos, diminuir o êxodo rural e valorizar as pesquisas e novas tecnologias de produção do biocombustível (Borsato et al., 2010). A gradativa elevação do percentual de adição de biodiesel ao diesel aponta o êxito do Programa Nacional de Produção e Uso do Biodiesel no Brasil. Somado a isso destaca-se a experiência positiva do país na fabricação e empregabilidade dos biocombustíveis (Guarieiro \& et al., 2008).

Vale destacar que "o uso massivo de combustíveis fósseis tem ocasionado diversos problemas ambientais e energéticos ao longo dos anos, justificando assim as pesquisas na área de combustíveis alternativos" (Galina \& et al., 2020, p. 1). Atualmente, verifica-se a demanda da sociedade por processos de produção cada vez mais limpos e sustentáveis. Assim, as "fontes de energia renováveis e que não representem ameaça ao meio ambiente, tornam-se um problema de cunho desafiador enfrentado pela humanidade" (Torres, Chaves \& Freitas, 2019, p. 2).

Incentivados pela descoberta de novas tecnologias capazes de diminuir impactos ambientais, os agricultores utilizam resíduos orgânicos (como o lodo de esgoto) associados aos fertilizantes tradicionais para compor substratos destinados ao plantio de diversas culturas (Vieites, 2010; Nobile, 2010). A aplicação desses resíduos no solo, além de ser uma opção de disposição adequada dos mesmos, pode proporcionar melhorias das características físico-químicas do substrato e tem-se tornado cada vez mais atraente, também, pelos baixos custos (Galdos et al., 2004).

"O biodiesel é um biocombustível limpo, renovável e biodegradável, podendo ser extraído de oleaginosas, gordura animal e estudos mais recentes demonstram que podem ser extraídos também de microalgas, o que demonstra o grande potencial que o biodiesel tem quando se trata de diversidade de matéria-prima" (Souza \& et al., 2020, p. 4).

Devido ao potencial da cultura verifica-se um crescente interesse no cultivo do Crambe no Brasil, no entanto percebese uma escassez de informações em relação aos aspectos nutricionais e formas de cultivo alternativas para a espécie (Soratto $e t$ al., 2013). Neste contexto, essa revisão de literatura tem como objetivo avaliar aspectos ecofisiológicos e botânicos do cultivo do Crambe abyssinica, abrangendo a produção de biodiesel na matriz energética brasileira.

\section{Metodologia}

Para suporte metodológico de toda a pesquisa bibliográfica, qualitativa e descritiva desse artigo foram utilizados os seguintes autores Gil (2008), Oliveira (2002) e Pereira et al. (2018) e os autores que tratam da temática sobre biodiesel, bem como, de outras fontes de energias renováveis.

Dessa forma, recorreu-se a pesquisa descritiva, mantendo abordagem qualitativa (Gil, 2008; Pereira et al., 2018). Na abordagem qualitativa, é possível "compreender e classificar processos dinâmicos experimentados [...] e apresentar contribuições no processo de mudança [...]" (Oliveira, 2002, p. 117). Destarte, esse trabalho trata-se de uma pesquisa qualitativa realizada por meio de revisão de literatura sistemática sobre o Crambe abyssinica e o seu potencial para a produção de biodiesel.

Para atingir o objetivo proposto, realizou-se a coleta de artigos nacionais e internacionais nas bases de dados Scopus, 
Google scholar, Science direct, Periódico da Coordenação de Aperfeiçoamento de Pessoal de Nível Superior (CAPES), Biblioteca Digital Brasileira de Teses e Dissertações (BDTD), World Wide Science e Scientific Electronic Library Online (SciELO) no período 1970 - 2019, incluindo também leis, decretos e documentos normativos. A escolha deste período justifica-se, pois, as primeiras publicações referentes ao tema surgem no início dos anos 70 .

Foram utilizadas para consultas nas bases de dados e plataformas as palavras-chaves: Crambe, biodiesel, biocombustíveis, matriz energética mundial, oleaginosas, agricultura sustável, utilização de resíduos na agricultura, lodo de esgoto, adubação alternativa, gesso e correção do solo. Procedeu-se, então, à análise do material, seguindo-se as etapas: leitura exploratória, leitura seletiva e leitura analítica/interpretativa.

\section{Resultados e Discussão}

\subsection{Histórico do biodiesel e perspectivas no Brasil}

O aproveitamento de óleos vegetais como matéria-prima para combustíveis não é recente. As primeiras experiências com motores de combustão por compressão foram conduzidas com óleo de amendoim. No ano 1900, Rudolph Diesel apresentou um protótipo que foi acionado com óleo de amendoim. Contudo, a abundância da oferta de petróleo e o seu preço acessível determinaram que, nos anos seguintes, os derivados do petróleo fossem os combustíveis preferidos, reservando os óleos vegetais para outros usos (Plá, 2003).

Devido à II Guerra Mundial houve corte de abastecimento e escassez de combustíveis no mundo, estimulando como consequência a busca por substitutos viáveis, no entanto, o desenvolvimento dos combustíveis de origem vegetal foi praticamente abandonado quando o fornecimento de petróleo foi restabelecido no final da Guerra (Plá, 2003).

Os combustíveis são de fundamental importância para atendimento das demandas energéticas da sociedade, porém, os de origem fósseis (sua fonte mais comum), devem ser de uso moderado por se tratar de um recurso não renovável e ter elevado potencial poluidor. Desta forma, faz-se necessário o aumento da utilização de energias sustentáveis na matriz energética mundial. Em vários países, programas de combustíveis verdes estão sendo desenvolvidos, inclusive no Brasil (Carneiro, \& et al. 2018, p. 2).

No Brasil, desde a década de 1920, o Instituto Nacional de Tecnologia (INT) já estudava e testava combustíveis alternativos e renováveis. Na década de 1970, pesquisadores da Universidade Federal do Ceará (UFC) desenvolveram pesquisas com o intuito de encontrar fontes alternativas de energia. Nas décadas seguintes pesquisadores de diversas universidades investigaram o tema de forma mais minuciosa e tecnológica (Holanda, 2004). Atualmente há um incentivo por parte do governo, através de programas vinculados aos Ministérios da Agricultura, da Ciência e da Tecnologia e da Energia, visando desenvolvimento tecnológico e social do biodiesel.

Em 13 de Janeiro de 2005, a lei 11.097 introduziu o biodiesel na matriz energética Brasileira. A referida Lei dispunha que, até 2013, haveria um percentual mínimo obrigatório de 5\% de adição de biodiesel ao óleo diesel comercializado em qualquer parte do território nacional. No ano de 2014 anunciou-se a ampliação de $6 \%$ e $7 \%$ no total da adição obrigatória de biodiesel ao óleo diesel. Em março de 2017 entrou em vigor a resolução que eleva a composição de biodiesel adicionado ao óleo diesel vendido ao consumidor para 8\% (B8). Ainda de acordo com a medida, as composições foram elevadas para $9 \% \mathrm{e}$ $10 \%$, respectivamente, a partir de $1^{\circ}$ de março de 2018 e $1^{\circ}$ de março de 2019 (MME, 2017).

De acordo com o governo, após a criação do Programa Nacional de Produção e Uso de Biodiesel (PNPB), foi formada uma rede de fomento e desenvolvimento que auxiliou inúmeros pequenos produtores. Em 2014 o Brasil possuía 83 mil agricultores e 77 cooperativas participando da produção de insumos para o biodiesel. Segundo a ANP, a cada $1 \%$ de biodiesel adicionado ao combustível convencional reduz-se em 0,7\% a emissão de gases nocivos (ANP, 2014). 


\subsection{Combustíveis fósseis versus bicombustíveis}

Os combustíveis fósseis (carvão, petróleo bruto e gás natural) surgiram quando, há milhões de anos atrás, a matéria orgânica deteriorada foi comprimida no subsolo sofrendo um conjunto de alterações físico-químicas (Ramage, 1997). Todas essas fontes de energia são consideradas reservas finitas e não renováveis, uma vez que é necessário muito tempo para reposição. Quimicamente os combustíveis fósseis são formados por uma soma complexa de hidrocarbonetos, além de compostos que contêm enxofre, nitrogênio e oxigênio. O petróleo, por exemplo, é uma substância oleosa e inflamável com forte odor e coloração muito escura (Brice, 1990 \& Bobin, 1999).

A Agência Internacional de Energia (AIE) publicou em seu relatório anual World Energy Outlook, de 2010, que a produção de combustíveis fósseis deve atingir seu pico por volta de 2035, sofrendo uma queda drástica em seguida. Vários estudos apontam o esgotamento das fontes de energia fóssil para os próximos 40 ou 50 anos, destacando-se a necessidade de desenvolver outras fontes alternativas (Aie, 2010).

Neste contexto, os biocombustíveis têm atraído a atenção de países de todo o mundo, pois se constituem numa alternativa bastante promissora para reduzir a dependência do petróleo, bem como proporcionar diversos benefícios ambientais e econômicos. Percebe-se uma perseverante busca global pela redução da emissão de dióxido de carbono $\left(\mathrm{CO}_{2}\right)$, metano $\left(\mathrm{CH}_{4}\right)$, sulfitos dentre outros gases que são gerados pela queima dos combustíveis fósseis (Lovelock, 2009).

Os biocombustíveis são produzidos a partir de uma grande diversidade de fontes de energia renováveis como as plantas, o sol, o vento, a água, a biomassa, os microrganismos e o hidrogênio, capazes de se regenerar rapidamente, ou seja, são inesgotáveis. De acordo com o Ministério de Minas e Energia (MME), as fontes renováveis de energia terão participação relevante na matriz energética global nas próximas décadas. A preocupação crescente com questões ambientais e os acordos internacionais para estimular as bases de desenvolvimento sustentável estão estimulando a realização de pesquisas de desenvolvimento tecnológico que vislumbram a redução de custos de produção de tecnologias para uso de fontes renováveis (MME, 2017).

Uma vantagem da produção de bicombustíveis a partir de matéria prima vegetal é que a produção pode ser controlada com o cultivo sendo realizado de acordo com a demanda e a oferta. Além disso, as plantas que originam os bicombustíveis absorvem gás carbônico do ar de modo a reduzir o efeito estufa, compensando o gás carbônico emitido na queima do combustível (MME, 2008).

Outras vantagens de utilizar bicombustíveis, no caso específico do Brasil, estão associadas às: (i) as grandes áreas disponíveis para cultivo que podem ser usadas para as culturas produtoras de bicombustíveis; (ii) a geração de emprego e renda no campo, reduzindo a taxa de êxodo rural; (iii) ao menor investimento financeiro em pesquisas para buscar novas tecnologias de produção de biocombustíveis e redução de geração de resíduos se comparado às pesquisas de prospecção de petróleo que são dispendiosas (MME, 2008). Em função dessas vantagens, "muitos estudos foram desenvolvidos de forma a propor técnicas para sua obtenção. Muitas tecnologias foram desenvolvidas com diferentes custos, eficiências, vantagens e restrições, que variam em função de matéria-prima, incentivos e regulamentações de diferentes países" (Torres, \& Chaves, \& Freitas, 2019, p. $3)$.

\subsection{A matriz energética brasileira}

A atual matriz energética brasileira ainda é suprida, em grande parte, pela energia não renovável. A Tabela 1 mostra a composição da oferta interna de energia nos períodos de 2015 e de 2016. 
Tabela 1 - Oferta Interna de Energia (OIE) no Brasil 2015-2016.

\begin{tabular}{|c|c|c|c|c|c|}
\hline \multirow[t]{2}{*}{ Especificação } & \multicolumn{2}{|c|}{ mil tep } & \multirow{2}{*}{$16 / 15 \%$} & \multicolumn{2}{|c|}{ Estrutura \% } \\
\hline & 2015 & 2016 & & 2015 & 2016 \\
\hline Não renovável & 175.903 & 162.975 & $-7,3$ & $\mathbf{5 8 , 7}$ & 56,5 \\
\hline Petróleo e derivados & 111.626 & 105.354 & $-5,6$ & 37,3 & 36,5 \\
\hline Gás natural & 40.971 & 35.569 & $-13,2$ & 13,7 & 12,3 \\
\hline Carvão mineral e derivados & 17.625 & 15.920 & $-9,7$ & 5,9 & 5,5 \\
\hline Urânio e derivados & 3.855 & 4.211 & 9,2 & 1,3 & 1,5 \\
\hline Outras não renováveis & 1.826 & 1.921 & 5,2 & 0,6 & 0,7 \\
\hline Renovável & 123.668 & 125.345 & 1,4 & 41,3 & 43,5 \\
\hline Hidroeletricidade & 33.897 & 36.265 & 7 & 11,3 & 12,6 \\
\hline Lenha e carvão vegetal & 24.900 & 23.095 & $-7,2$ & 8,3 & 8,0 \\
\hline Derivados da cana de açúcar & 50.648 & 50.318 & $-0,7$ & 16,9 & 17,5 \\
\hline Outras fontes renováveis & 14.223 & 15.667 & 10,1 & 4,7 & 5,4 \\
\hline TOTAL & 299.570 & 288.319 & $-3,8$ & 100,0 & 100,0 \\
\hline
\end{tabular}

Fonte: Ministério de Minas e Energia- Resenha Energética Brasileira- Julho 2017.

Observa-se na Tabela 1 que um pequeno aumento na participação das fontes renováveis, como resultado, principalmente, da forte retração das fontes não renováveis $(-7,3 \%)$. As demais fontes de energia renovável entre elas a eólica, biodiesel, lixívia e outros resíduos de biomassa, apresentaram crescimento de 10,1\% (MME, 2017).

A oferta da hidroeletricidade reverteu as taxas negativas da oferta de energia de 3,2\% em 2015 e de 5,6\% em 2014. A lenha e o carvão vegetal apresentaram recuo de 7,2\%. O uso de carvão vegetal na produção de ferro-gusa, com baixa de $16,7 \%$ apresentou a maior contribuição relativa. Neste contexto, as fontes renováveis passaram a responder por uma participação de 43,5\% na demanda total de energia de 2016 ante os 41,3\% verificados em 2015 (MME, 2017).

Em razão da menor geração de energia elétrica por fontes fósseis no Brasil, em 2016, a relação entre as emissões de $\mathrm{CO}_{2}$ pelo uso de energia e a demanda total de energia ficou em 1,48 tCO $\mathrm{tep}^{-1}$, indicador inferior ao de $2015\left(1,55 \mathrm{tCO}_{2} \mathrm{tep}^{-1}\right)$. As expressivas participações da energia hidráulica e da bioenergia na matriz energética brasileira proporcionam indicadores de emissões bem menores do que a média mundial $\left(2,34 \mathrm{tCO}_{2} \mathrm{tep}^{-1}\right)$ e dos países desenvolvidos $\left(2,23 \mathrm{tCO}_{2} \mathrm{tep}^{-1}\right)$. Para efeitos de comparação é importante destacar que em 2014, a China e os Estados Unidos, com emissões de 14.101 milhões (M) de $\mathrm{tCO}_{2}$, responderam por 43,6\% das emissões mundiais, totalizando $32.348 \mathrm{MtCO}_{2}$. Cabe ressaltar que, em 2010, esses países tiveram participação menor respondendo por $41,8 \%$ do total das emissões (MME, 2017).

Em relação à presença de fontes renováveis na matriz de energia, é notável a vantagem do Brasil, registrando 43,5\% de participação em 2016, contra 16,9\% dos demais países. O mundo registra indicador médio de 14,2\% (MME, 2017).

\subsection{Tratados e protocolos ambientais que incentivam o uso das energias renováveis}

Segundo Le Prestre (2000), pode-se definir três fases na evolução da política ambientalista internacional: a primeira, vai do fim do século XIX à Conferência da Unesco de 1968. Em seguida, o início das discussões das questões ambientais no cenário internacional, ao final dos anos 1960, deu origem a um período de ativismo intenso, após o qual decorreu certo cansaço em um contexto internacional difícil (1968-1986). Finalmente, desde 1987, assiste-se a uma ressurgência e a uma nova presença das questões ambientais, caracterizadas pela multiplicação, aceleração e complexidade das interações internacionais e das questões tratadas. 
Em meados de 1980 discutiu-se efetivamente sobre as mudanças climáticas globais na esfera internacional. Tal processo resultou na realização de conferências mundiais convocadas pela ONU. Esses encontros estabeleceram normas sobre a redução de emissões de gases de efeito estufa e traçaram metas a serem atingidas por países de vários continentes. A partir de então os temas ambientais ganharam mais espaço nos debates entre os principais líderes mundiais. Também contribuíram para estabelecer articulações entre setores que antes se encontravam à margem desse processo (Le Prestre, 2000).

A Conferência de Estocolmo de 1972 foi o marco inicial, sendo a primeira reunião que repercutiu diretamente na formação de estruturas internacionais ambientais (Oliveira, 2011). Vinte anos depois aconteceu a Eco 92, realizada no Rio de Janeiro e teve como principal objetivo obter, através de negociações, a redução na concentração de gases estufa na atmosfera, limitando a interferência do homem nos sistemas climáticos (Mazzuoly, 2004). Logo após ocorreu o encontro de Kyoto (1998), o Rio+10 (2002), a Conferência de Bali (2007), a Conferência de Copenhague (2009), a Conferência do Clima da ONU de Durban (2011), o Rio +20 (2012) e a Conferência do Clima da ONU em Paris (2015) (MMA, 2015).

De 1972 até hoje os objetivos das conferências não foram alterados, ao contrário, adicionaram-se medidas em busca de soluções para o aquecimento global, efeito estufa, mudanças climáticas, controle da poluição, preservação de áreas verdes, preservação das áreas polares, diminuição da pobreza mundial entre outros. A principal ferramenta atual é um sistema de metas onde cada país se estrutura considerando sua promessa de redução das emissões, que são revisadas de cinco em cinco anos (MMA, 2012). O ponto negativo dos protocolos é que não existe nenhum tipo de punição àqueles países que descumprirem as medidas de redução de emissão de gases, dentre os mais poluidores destacam as potências EUA e China.

\subsection{Crambe (Crambe abyssinica): ocorrência, características botânicas e morfológicas}

O Crambe abyssinica Hochst, também conhecido como Abyssinian kale, é um membro da família Brassicaceae que possui aproximadamente de 30 espécies, distribuídas principalmente na região do Mediterrâneo, sendo o único membro cultivado (Desai, 2004).

Figura 1 - Crambe abyssinica,

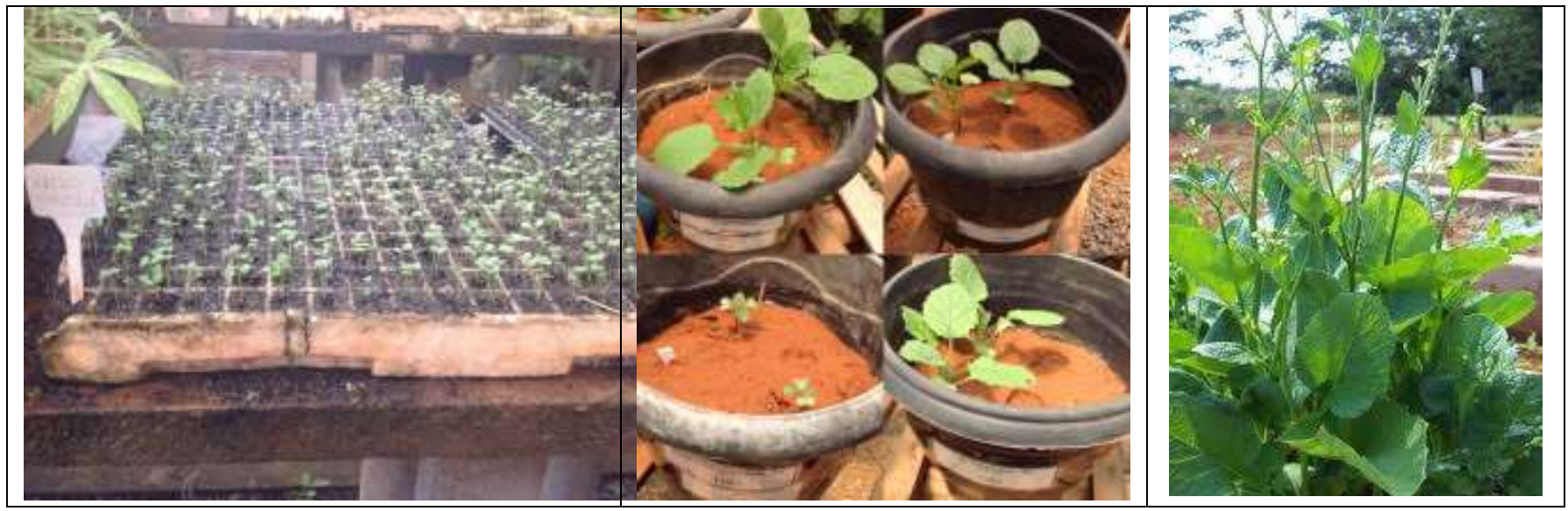

Fonte: Autores (2021).

A espécie chegou ao Brasil na década de 1990 através de materiais oriundos do México. Com este material genético, os pesquisadores brasileiros da Fundação Mato Grosso do Sul e Paraná desenvolveram a primeira cultivar nacional, chamada FMS Brilhante (Figura 1), produtiva e adaptada às condições do país (Pitol et al., 2010). Na época, a planta era estudada somente para fins de rotação de cultura. Atualmente, as pesquisas estão voltadas para a produção de óleo para fins industriais, como biodiesel, cosméticos, lubrificantes e isolantes térmicos (Oliva, 2010). 
A cultivar FMS Brilhante é uma planta herbácea, com aproximadamente um metro de altura, cuja haste ramifica-se próxima ao solo formando dezenas de galhos, que novamente se ramificam, formando galhos terciários (Desai et al., 1997). As folhas do Crambe abyssinica são ovais e assimétricas com lâmina foliar lisa de aproximadamente $10 \mathrm{~cm}$ de comprimento e $7,6 \mathrm{~cm}$ de largura. O pecíolo possui aproximadamente $20 \mathrm{~cm}$ de comprimento e é pubescente (Oplinger et al., 2008). Já as flores Crambe são amarelas ou brancas e produzem um grande número de sementes pequenas.

\subsubsection{Ecologia da espécie}

O Crambe abyssinica é uma espécie anual, floresce em média aos 35 dias após a semeadura e seu ciclo pode alcançar até 95 dias. A planta apresenta características positivas como rusticidade, fácil adaptabilidade a solos de baixa fertilidade, resistência à seca e pragas e alta produtividade de óleo nas sementes ( 35 a 40 \%) (Neves et al., 2007). O fruto Crambe é uma síliqua verde que se torna amarelo com a maturidade e seu tamanho varia consideravelmente no diâmetro (0,8 a 2,6 mm), sendo influenciado pelo número de grãos por planta, fertilidade do solo e regime hídrico (Desai et al., 1997).

As sementes são ortodoxas, albuminosas, têm o eixo embrionário curvo, e apresentam a plúmula protegida por uma fina cobertura mucilaginosa (Cruciferae, 1985). As sementes ainda são envolvidas por uma estrutura tegumentar denominada pericarpo, cujas funções são proteção contra abrasões e choques, barreira contra microrganismos, preservação do poder germinativo. A tolerância Crambe da espécie a estiagem está relacionada à sua capacidade de enraizamento profundo. Com um sistema radicular pivotante, sua raiz atinge, em média, 150 centímetros de comprimento.

\subsubsection{Características da cultura e condições de cultivo}

De acordo com Toebe et al. (2010) e Pilau et al. (2011), a cultura de Crambe abyssinica está ganhando destaque no Brasil devido à sua tolerância à seca e ao frio sendo capaz de resistir a temperaturas de até $-6{ }^{\circ} \mathrm{C}$, além de sua adaptabilidade, precocidade e produtividade. Além do potencial produtivo, a espécie, quando cultivada em rotação de culturas, ocupa áreas ociosas e contribui na melhoria dos solos pela sua cobertura verde. Considerada uma planta recicladora de nutrientes do solo, aproveita adubações residuais de culturas anteriores e responde a adubação no plantio. Segundo Rogério et al. (2013), observase nas plantações de Crambe abyssinica uma redução no uso de fertilizantes e água quando comparada a outras oleaginosas.

O cultivo do Crambe abyssinica é totalmente mecanizado e os custos de produção relativamente baixos (Onoveroli, 2012). Para o estabelecimento de um hectare da cultura são necessários entre 12 e 15 quilos de sementes, dispostas em espaçamentos que variam de 15 a $70 \mathrm{~cm}$. Segundo Roscoe et al. (2007), a espécie produz de 1.200 a $1.500 \mathrm{~kg}$ de sementes, resultando em aproximadamente $570 \mathrm{~kg}$ de óleo, com custo de produção de $\mathrm{R} \$ 250,00$ por hectare. O retorno econômico para o produtor varia de $30 \%$ a $60 \%$ em relação ao investimento inicial (Knights, 2002).

A oleaginosa apresenta sensibilidade quanto à acidez do solo e, para o seu cultivo, os solos ácidos devem ser corrigidos até $\mathrm{pH}$ entre 6,0 e 7,5. Visando um desenvolvimento adequado, o solo também deve apresentar fertilidade mediana, sendo que o solo na profundidade entre 20 a 40 centímetros deve conter baixa saturação de $\mathrm{Al}^{3+}$ (Pitol et al., 2010). Recomenda-se densidade de 8 a 22,5 kg ha-1 de sementes, e profundidade de semeadura de $3 \mathrm{~cm}$ (Knights, 2002). A espécie necessita de aproximadamente 150 a $200 \mathrm{~mm}$ de água da semeadura até o estabelecimento da planta e, necessita de umidade do solo próximo à capacidade de campo para seu desenvolvimento inicial. Após o período de florescimento da planta, a ausência de chuva propicia o melhor desenvolvimento e redução na incidência de doenças (Moers et al., 2012).

Quando os elementos minerais essenciais, como o nitrogênio, fósforo e potássio (NPK) não estão disponíveis, a planta tem dificuldade de expressar o seu potencial e completar seu ciclo de vida (Malavolta, 1980). Neste sentido, a aplicação de fertilizantes de forma eficiente é fundamental para a garantia de alta produtividade. Para o Crambe, as respostas em relação aos 
fertilizantes são pouco conhecidas. Sabe-se que é uma planta que absorve grande quantidade de nitrogênio considerando o elevado teor de proteínas nos grãos (Souza et al., 2009). Devido à escassez de estudos, até pouco tempo utilizava-se as recomendações de NPK (50 kg ha ${ }^{-1}$ de $\mathrm{P}_{2} \mathrm{O}_{5}, 90 \mathrm{~kg} \mathrm{ha}^{-1}$ de $\mathrm{K}_{2} \mathrm{O}$ e 90 a $112 \mathrm{~kg} \mathrm{ha}^{-1}$ de $\mathrm{N}$ ) usadas na cultura da soja. Um estudo mais recente, de Soratto et al. (2013), propõe a utilização de $300 \mathrm{~kg}$ de NPK (4-14-8) por hectare destinado à plantação da espécie Cramber abyssinica. No que diz respeito ao enxofre, a recomendação é de 22,5 a $28 \mathrm{~kg} \mathrm{ha}^{-1} \mathrm{em}$ solos com baixo teor do elemento mineral (Oplinger et al., 1991).

\subsubsection{Processamento de grãos e extração de óleo de Cramber abyssinica}

Ao término do ciclo da cultura, as folhas Crambe amarelam, secam e, em seguida, caem. Os frutos também sofrem o mesmo processo. A partir desta etapa atinge-se o ponto de colheita que pode ser realizado por colhedora automotriz comum, necessitando apenas de ajustes em sua peneira. O processamento desta espécie é semelhante ao de outras oleaginosas. Os principais métodos utilizados na extração do óleo são a prensagem mecânica e a extração por solventes. No entanto, antes do processo de extração, é necessário realizar o descascamento, limpeza, secagem e desintegração dos grãos (Carvalho, 2011).

A extração mecânica é a etapa onde ocorre a separação de líquidos e de sólidos através do emprego de forças de compressão, tendo como principal resultado o resíduo conhecido como torta (Brennan et al., 1990). Para a extração mecânica utilizam-se equipamentos rudimentares como as prensas hidráulicas, que são mais utilizadas em pequenas instalações, e prensas contínuas que possuem maior capacidade. As prensas contínuas possuem um parafuso sem fim que esmaga o material, liberando o óleo. As prensas hidráulicas (prensagem descontínua) são dotadas de um cilindro perfurado onde um êmbolo se desloca, fazendo pressão sobre os frutos que ficam dispostos no interior de um saco de pano ou lona (Carvalho, 2011).

O procedimento de extração por solvente de diversas origens como hexano, propano e diclorometano é uma operação na qual ocorre a separação ou isolamento de substâncias, muito empregado na indústria de alimentos. A extração ocorre pela reação do solvente com a semente, que é previamente triturada promovendo a remoção do óleo através da ligação molecular e difusão. Em processos de prensagem hidráulica, a torta, material que sobra da prensagem, ainda pode conter aproximadamente $6 \%$ de óleo residual, enquanto em processos com extração utilizando solventes esta quantidade residual na torta é inferior a $1 \%$ (Tandy, 1991). Existem ainda outras formas de separação do óleo em relação à torta, como destilação; extração supercrítica com emprego de $\mathrm{CO}_{2}$ como solvente e por fervura caseira (Bernardo-Gil et al., 2002).

\subsection{4 Óleo de Crambe abyssinica e produção de biodiesel}

A semente da Crambe abyssinica possui elevado teor de ácidos graxos de alto peso molecular (aproximadamente 35\%), com predominância do ácido erúcico, correspondendo a aproximadamente 55\% do total de ácidos graxos, seguido do ácido oleico, com aproximadamente 17\% (Toebe, 2010). A grande porcentagem de ácido erúcico torna o óleo Crambe impróprio para consumo humano, sendo digerível apenas por ruminantes. No entanto, torna-se uma excelente alternativa para a produção de biodiesel devido às suas propriedades como tolerância em temperaturas elevadas e maior degradabilidade em comparação aos seus homólogos a base de petróleo (Onoveroli, 2012; Lazzeri et al., 1997).

Segundo Brito (2020 \& et al., 2020, p. 3) "existem diferentes fontes de matéria-prima para a produção de biodiesel, dentre elas pode-se citar" o Crambe abyssinica. As vantagens do biodiesel produzido a partir do óleo de Crambe abyssinica, são a disponibilidade e a renovabilidade da matéria prima, seu poder calorífico superior, menor teor de enxofre se comparado com diesel fóssil, baixo ponto de fusão $\left(-12^{\circ} \mathrm{C}\right)$ e alta estabilidade oxidativa (Roscoe et al., 2010; No, 2011). A pesquisa realizada por Wazilewski et al. (2012), concluiu que o biodiesel Crambe produzido a partir desta espécie atende às normativas quanto ao tempo mínimo exigido para o período de indução, tempo que um óleo leva para iniciar o processo de degradação, 
que corresponde a seis horas na temperatura de $110^{\circ} \mathrm{C}$. Além disso, o ponto de fulgor mínimo de $100{ }^{\circ} \mathrm{C}$ e densidade entre 860 a $900 \mathrm{~kg} \mathrm{~m}^{-3}$ também se encontram dentro das faixas ótimas. Contudo, apresenta índices de acidez superiores a $1 \mathrm{mg} \mathrm{KOH} \mathrm{g}^{-1}$, com o valor aceitável máximo de $0,8 \mathrm{mg} \mathrm{KOH} \mathrm{g}^{-1}$, necessitando de neutralização.

\subsubsection{Outras aplicações para óleo de Crambe}

Devido a sua habilidade de formar polímeros a seco, o óleo de Crambe pode ser usado como óleo para formação de pastas e pintura, como lubrificante industrial, como inibidor de corrosão e como ingrediente para fabricação de borracha sintética. Ele também pode ser utilizado para produzir filmes plásticos, nylon, adesivos e para isolamento elétrico. Ainda pode ser empregado na produção de emolientes, em especial para produtos destinados à pele e condicionadores de cabelo (Regitanod'ace, 2008).

\subsection{Biodiesel}

\subsubsection{O biodiesel e as vantagens de sua utilização}

"Os estudos do biodiesel baseado em óleos vegetais e gorduras animais tiveram o seu início investigativo no período anterior a década de 1970, mais precisamente por Rudolf Diesel (1858-1913)" (Brito et al., 2020, p. 4).

A definição mais usualmente aplicada à palavra biodiesel é a de um combustível biodegradável, produzido a partir de fontes naturais e renováveis, capaz de substituir, diretamente ou em mistura, o diesel derivado de petróleo na operação de motores ciclo diesel. Knothe et al. (2007) relatam que o biodiesel é um combustível praticamente livre de enxofre, substâncias aromáticas e compostos sulfurados. Jasper (2009) explica que o fato de o biodiesel não possuir enxofre e compostos aromáticos, proporciona uma combustão mais limpa e sem compostos cancerígenos, classificado como um combustível ecológico.

De acordo com Pinto et al. (2001), o biodiesel pode ser utilizado em qualquer tipo de motor a diesel, com pouca ou nenhuma necessidade de adaptação. Considerando a sua reduzida inflamabilidade em relação aos congêneres de natureza petrolífera, o transporte, armazenamento e manuseio mostram-se mais seguros. A possibilidade de produção em pequena escala também vem sendo destacada em vários países, melhorando a economia de regiões mais isoladas, possibilitando a produção para consumo próprio de produtores rurais (Chiaranda et al., 2005).

\subsubsection{Produção de biodiesel}

A produção do biodiesel é realizada pelo processo de transesterificação (Figura 2), na qual os ácidos graxos que compõem a gordura ou óleo vegetal, com ajuda de um solvente como o etanol, são separados da glicerina (composto orgânico pertencente à função álcool). O processo origina: (i) os ésteres (nome químico do biodiesel); e (ii) a glicerina (poliálcool utilizado no mercado de sabões); (iii) coprodutos como torta e farelo que podem gerar outras fontes de renda importantes para os produtores (Abdalla et al., 2008).

De acordo com Geris (2007), transesterificação é um termo geral usado para descrever uma importante classe de reações orgânicas em que um éster é transformado em outro através da troca do resíduo alcoxila. Quando o éster original reage com um álcool, o processo de transesterificação é denominado alcoólise. Para a obtenção de biodiesel, a reação de transesterificação de óleos vegetais com álcoois primários pode ser realizada tanto em meio ácido quanto em meio básico, acelerando consideravelmente a conversão, como também contribuindo no aumento do rendimento da mesma. 
Figura 2 - Reação de transesterificação.

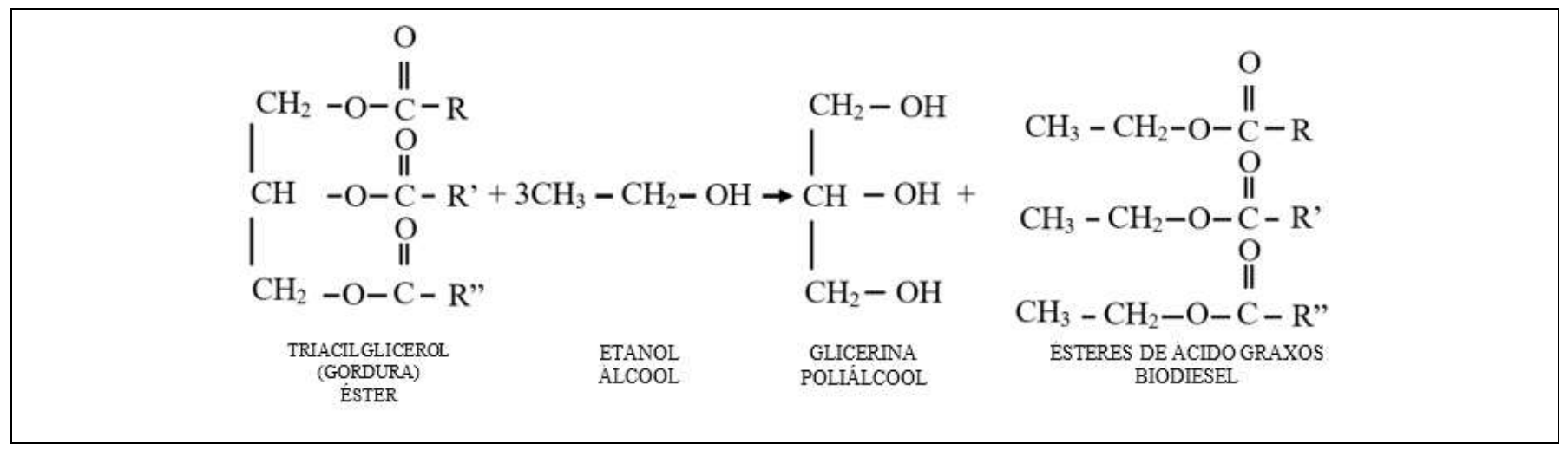

Fonte: Abdalla et al. (2008).

As matérias-primas necessárias para produção do biodiesel provêm de óleos vegetais, gordura animal, óleos e gorduras residuais. As fontes vegetais são as mais variadas e consideradas as mais viáveis até o momento (Chiaranda et al., 2005). As principais matérias-primas utilizadas para a produção do biodiesel de acordo com Abdalla et al. (2008) são o óleo de soja, óleo de algodão, sebo bovino, óleo de palma, e óleo de girassol. Outras oleaginosas também apresentam potencial para a produção do biodiesel, dentre elas o babaçu, canola, gergelim, macaúba, pinhão manso e Crambe.

A produção de biodiesel a partir de algas também tem sido pesquisada. Estas apresentam um potencial de produção de óleo muito superior por área equivalente de cultivo se comparadas às culturas tradicionais, produzidas em solo e utilizadas na produção do biodiesel. As algas despertaram o interesse mundial e as pesquisas e estratégias dos investidores são, em sua maioria, mantidas em segredo (Defanti, 2010).

\subsubsection{Métodos clássicos de análise dos óleos}

- Índice de acidez.

O índice de acidez mostra o estado de conservação de óleos e gorduras e pode ser definido como o número de miligramas de hidróxido de potássio necessário para neutralizar os ácidos graxos livres de 1,0 g da amostra (IAL, 2008). A hidrólise parcial dos glicerídeos é acelerada por aquecimento e pela luz, e a rancidez é quase sempre acompanhada pela formação de ácido graxo livre (Moretto \& Fett, 1998). Entretanto, tal característica não pode ser considerada uma constante dos óleos vegetais, podendo variar conforme o grau de maturação e condições de armazenamento das sementes ou frutos usados para extração da matéria graxa, a temperatura e tempo do processo de extração e das condições de armazenagem do óleo.

\section{- Índice de peróxido}

O índice ou teor de peróxidos é um indicador do grau de oxidação do óleo ou gordura, e sua presença, indício de deterioração, pode ser verificada com a mudança do sabor e do odor característicos dos óleos (Reda, 2004). A determinação do índice de peróxidos ocorre pela adição de solução de iodeto de potássio saturada à amostra. Os íons iodeto reagem com os peróxidos, produzindo $\mathrm{I}_{2}$, que ficam em solução. Ao adicionar o amido, como indicador, este em presença de $\mathrm{I}_{2}$ assumirá a cor azul. Ao titular-se a solução com tiossulfato de sódio, este é oxidado a tetrationato de sódio e o iodo é reduzido a $\mathrm{I}^{-}$, promovendo a perda da cor azulada. Assim, a quantidade de tiossulfato consumida é proporcional à quantidade de peróxidos presentes na amostra (Baccan et al., 2003). 


\section{- Índice de iodo}

O índice de iodo é usado para medir o grau de insaturação de óleos e gorduras. É um importante indicador de provável desenvolvimento de degradação da matéria graxa, sendo usado para determinar as propriedades químicas e físicas dos óleos (Reda, 2004). Valores elevados para o índice de iodo podem indicar maior propensão à ocorrência de processos oxidativos na molécula do ácido graxo insaturado. Os ácidos graxos contendo ligações duplas carbono-carbono reagem com iodo, de modo que, quanto maior o número de insaturações maior é o índice de iodo, podendo ser expresso em termos do número de centigramas de iodo absorvido por grama da amostra (\% iodo absorvido), em condições específicas de ensaio (IAL, 2008).

\section{- Viscosidade cinemática}

A viscosidade de um material pode ser definida como a propriedade física dos fluidos que caracteriza a sua resistência ao escoamento. Esta propriedade é variável nos óleos vegetais e dependente do grau de insaturação e tamanho das cadeias graxas que os compõem, podendo também ser influenciada pela presença de ramificações e posicionamento das insaturações (Park \& Leite, 2010).

Os ácidos graxos saturados se encontram em uma conformação linear, flexível em estado de menor energia, possibilitando uma interação molecular mais efetiva, enquanto os ácidos graxos insaturados apresentam dobramentos na cadeia carbônica, para cada dupla ligação presente. A presença dessas insaturações na molécula torna as interações moleculares menos eficientes e a viscosidade menor (Curi et al., 2002).

A determinação da viscosidade dos óleos vegetais é importante e pode limitar a escolha da matéria-prima que dará origem ao biodiesel. A viscosidade dos óleos pode favorecer as propriedades de lubricidade do biocombustível, entretanto, valor elevado para este parâmetro entre 3,0 a $6,0 \mathrm{~mm}^{2} \mathrm{~s}^{-1}$ a $40{ }^{\circ} \mathrm{C}$, pode gerar um produto fora das especificações da Agência Nacional de Petróleo, mesmo quando estes são submetidos à reação de transesterificação. Tais características tendem a comprometer o fluxo e atomização do biodiesel. Para amenizar este problema são utilizadas etapas de tratamento prévio desses óleos, como o processo de refino.

\section{- Determinação do tempo de indução oxidativa}

Existem vários métodos empregados para determinar a resistência à oxidação, ou seja, o tempo de indução oxidativa (OIT) de uma substância. Eentre eles destacam-se o método de estufa, Active Oxygen Method (AOM), Oil Stability Instrument (OSI), Rancimat, PetromOXY e Calorimetria Exploratória Diferencial sob Pressão (PDSC) (Knothe, 2007).

O tempo de indução oxidativa (OIT) é definido como o tempo do início da oxidação de uma amostra exposta a um gás oxidante em uma determinada temperatura. Este parâmetro é também utilizado como ferramenta para controle de qualidade e classificação da eficiência de vários inibidores de oxidação que são adicionados em polímeros, lubrificantes, gorduras, óleos e biodiesel. Segundo American Oil Chemists' Society - AOCS (1999) a determinação da estabilidade oxidativa de óleos e gorduras, segue a metodologia Cd 12b-92. De acordo com esta metodologia, pode-se utilizar na determinação da estabilidade oxidativa de óleos e gorduras, os equipamentos Rancimat ou OSI (Antoniassi, 2001) na medição do período de indução (PI). Desse modo, obtém-se o tempo necessário para formação de uma concentração de radicais reativos, detectados pelo equipamento

\section{- Análise cromatográfica dos óleos vegetais}

O desenvolvimento de técnicas que permitam a elucidação qualitativa e quantitativa de espécies químicas, com destaque para a Cromatografia em Fase Gasosa de Alta Resolução, acoplada o ao espectrômetro de massa (CGAR-MS), possibilitou o avanço do estudo de óleos e gorduras, desvendando sua composição completa em ácidos graxos, em tempo relativamente curto. De modo a viabilizar a análise cromatográfica de óleos vegetais, ganha relevância o processo de 
esterificação dos mesmos, onde os ácidos graxos são convertidos em compostos mais voláteis, como ésteres metílicos ou etílicos destes ácidos graxos (Milinsk, 2007), favorecendo o processo de caracterização da amostra. O processo de esterificação é necessário para evitar reações entre os ácidos graxos presentes nos óleos e a fase estacionária das colunas capilares utilizadas nas análises de CGAR.

\subsubsection{Especificação do biodiesel}

A Tabela 2, a seguir, mostra os parâmetros de especificações do biodiesel segundo a Agência Nacional de Petróleo (ANP).

Tabela 2 - Especificação do biodiesel segundo a portaria ANP n²55 de 15/09/13.

\begin{tabular}{lcc}
\hline Característica & Unidade & Limite \\
\hline Viscosidade Cinemática a $40^{\circ} \mathrm{C}$ & $\mathrm{mm}{ }^{2 / \mathrm{s}}$ & 3,0 a 6,0 \\
Teor de água, máx. & $\mathrm{mg} / \mathrm{kg}$ & $(2)$ \\
Ponto de fulgor, mín. (3) & ${ }^{\circ} \mathrm{C}$ & 100,0 \\
Teor de éster, mín. & $\%$ massa & 96,5 \\
Resíduo de carbono, máx. (4) & $\%$ massa & 0,050 \\
Cinzas sulfatadas, máx. & $\%$ massa & 0,020 \\
Enxofre total, máx. & $\mathrm{mg} / \mathrm{kg}$ & 10 \\
Corrosividade ao cobre, $3 \mathrm{~h}$ a $50^{\circ} \mathrm{C}$, máx. & - & 1 \\
Ponto de entupimento de filtro a frio, máx. & $\mathrm{o} \mathrm{C}$ & $(7)$ \\
Índice de acidez, máx. & $\mathrm{mg} \mathrm{KOH} / \mathrm{g}$ & 0,80 \\
Glicerol total, máx. & $\% \mathrm{massa}$ & 0,25 \\
Metanol e/ou Etanol, máx. & $\% \mathrm{massa}$ & 0,20 \\
Índice de Iodo & $\mathrm{g} / 100 \mathrm{~g}$ & $\mathrm{Anotar}$ \\
Estabilidade à oxidação a $110^{\circ} \mathrm{C}$, mín. & $\mathrm{h}$ & 6 \\
\hline
\end{tabular}

Fonte: Agência Nacional do Petróleo (2013).

Observando a Tabela 2 é possível destacar que apesar da facilidade em se produzir biodiesel, um grande problema é produzi-lo de modo a se encaixar perfeitamente em todos os parâmetros estipulados pela ANP.

\section{Conclusões}

O objetivo desse trabalho foi realizar um levantamento das principais características da oleaginosa Crambe abyssinica, abordando desde a ecologia e morfologia da espécie até as condições de cultivo e produção de biodiesel. O estudo apontou qualidades, que favorecem seu cultivo para produção de biodiesel, como: alta produtividade de matéria seca e óleo, e baixos custos de produção.

Somado a isso, a aplicação industrial (matéria prima para tintas, lubrificantes e isolantes elétricos, possibilidade da colheita mecanizada, ciclo curto e a resistência a variação de temperatura são características que agregam valor ao cultivo da espécie.

O biodiesel, um biocombustível líquido formado a partir da transesterificação de óleos vegetais e gorduras animais, é uma fonte de energia renovável que tem potencial para substituir o uso de combustíveis fósseis. Dentre suas principais características, destacam-se a biodegradabilidade e o baixo teor poluente. A utilização de biocombustíveis, fortalece a preservação e manutenção do meio ambiente e contribui para que as atuais e futuras gerações não sejam prejudicadas pelo uso 
indiscriminado dos recursos naturais e o aumento da poluição do planeta.

\section{Sugestões para trabalhos futuros}

Estudos sobre uma melhor diversificação da matriz energética brasileira; propostas de trabalhos que estudem sobre as políticas governamentais de incentivo ao aumento da utilização de biocombustíveis e outras fontes de energia renováveis. Essas sugestões ocorrem tendo em vista que as fontes não renováveis advindas do petróleo ainda predominam em relação às fontes renováveis.

\section{Referências}

Abdalla, A. L., Silva Filho, J. C., Godoi, A. R., Carmo, C. A. \& Eduardo, J. L. P. (2008). Utilização de subprodutos da indústria de biodiesel na alimentação de ruminantes. Revista Brasileira de Zootecnia, 37, 260-258. https://doi.org/10.1590/S1516-35982008001300030.

AIE. (2010). World Energy Outlook OECD-IEA, International Energy Agency.

ANP - Agência Nacional do Petróleo, Gás Natural e Biocombustíveis (2014). Anuário estatístico brasileiro do petróleo, gás Biodiesel no Brasil: uma análise da regulação e seus reflexos na diversificação das matérias-primas usadas no processo de produção natural e biocombustíveis 2014 . http://www.brasil.gov.br/economia-e-emprego/2014/05/governo-aumenta-porcentagem-de-biodiesel-no-diesel.

Bernardo-Gil, M., Ribeiro, G. \& Esquível, M. M. (2002). Produção de extratos para a indústria alimentar: uso de fluídos supercríticos. Boletim de Biotecnologia. 73, 14-21.

Bispo, A. S., Delfino, L. D., Costa, B. J., Suchek, E. M., Adão, D. C., Fonseca, F. C., Zagonel, G. F., Adad, L. B., Maia, M., Silva, P. R. \& Vechiatto, W. W. D. (2010). Caracterização de óleos vegetais extraídos mecanicamente sob condições variadas, visando a produção de biodiesel. In: $4^{\circ}$ Congresso da Rede Brasileira de Tecnologia de Biodiesel; $7^{\circ}$ Congresso Brasileiro de Plantas Oleaginosas, Óleos, Gorduras e Biodiesel, Belo Horizonte, MG. Anais... Belo Horizonte, MG: TECPAR.

Bobin, J. A (1999). Energia”. Instituto Piaget.

Borsato, D., Dall'antonia, L. H., Guedes, C. L. B., Maia, E. C. R., Freitas, H. R., Moreira, I. \& Spacino, K. R. (2010). Aplicação do delineamento simplex centroide no estudo da cinética da oxidação de biodiesel B100 em mistura com antioxidantes sintéticos. Química Nova. 33(8), 1726-1731. http://dx.doi.org/10.1590/S0100-40422010000800020.

Brennan, J. G. Butters, J. R. \& Cowell, N. D. \& Lilley, A. E. V. (1990). Food engineering operations. Linton Road, England: Elsevier Applied Science.

Brice, R. (1990). Do petróleo ao plástico. Círculo de Leitores.

Brito, M. R., \& et al. (2020). Análise das propriedades do biodiesel de polpa de abacate como lubrificante: teste pino no disco. Research, Society and Development, 9 (7), e136973886. https://doi.org/10.33448/rsd-v9i7.3886

Carneiro, G. A., Silva, J. J. R., Oliveira, G. de A., \& Pio, F. P. B. (2018). Uso de Microalgas para Produção de Biodiesel. Pesquisa, Sociedade e Desenvolvimento, 7 (5), e1075181. https://doi.org/10.17648/rsd-v7i5.250

Carvalho, C. O. de (2011). Comparação entre Métodos de Extração do Óleo de Mauritia Flexuosa L. F. (Arecaceae - Buriti) para o Uso Sustentável na Reserva de Desenvolvimento Tupé: Rendimento e Atividade Antimicrobiana. Dissertação (Mestrado), Pós-Graduação em Biotecnologia e Recursos Naturais. UEA. Manaus - AM.

Chiaranda, M., Andrade Junior, A. M. \& Oliveira, G. T. (2005). A Produção de Biodiesel e aspectos do PNPB.

CONAMA - Conselho Nacional do Meio Ambiente (2015). Resolução n 375, de 29 de agosto de 2006. http://www.mma.gov.br/port/conama/legiano/.

Cruciferae. Handbook of seed technology for genebanks Vol. II. Compendium of Specific Germination Information and Text Recommendations.1985. Chap. 32. http://www2.bioversityinternational.org/publications/Web_version/52/ .

Defanti, A. \& Leonardo, S. (2010). Biocombustíveis a partir de algas fotossintetizantes. Revista de Divulgação do Projeto Universidade Petrobras e IF Fluminense, Rio de Janeiro, p. 11-21, nov. 2010. http://biomassaworld.com.br/wp-content/uploads/2016/04/Produ\%C3\%A7\%C3\%A3o-debiocombust $\%$ C $3 \%$ ADveis-a-partir-de-algas-fotossintetizantes.pdf

Desai, B. B.(2004). Seed's handbook: biology, production processing and storage. (2a ed.), Marcel Dekker. 787 p.

Desai, B. B., Kotecha, P. M. \& Salunkhe, D. K. (1997). Seeds handbook: biology, production processing and storage. Marcel Dekker. 627 p.

Galdos, M. V., Maria, I. C. \& Camargo, O. A. (2004). Atributos químicos e produção de milho em um Latossolo Vermelho eutroférrico tratado com lodo de esgoto. Revista Brasileira de Ciência de Solo. 28, 569-577.

Galina, D., Benedito, V. M., Freitas, R. R. de, \& Porto, P. S. da S. (2020). Analysis of the influence of temperature and time on direct transesterification of Nannochloropsis Oculata for biodiesel production. Research, Society and Development, 9(7), e655974648. https://doi.org/10.33448/rsd-v9i7.4648 
Guarieiro, L. L. N., Pinto, A. C., Aguiar, P. F. \& Ribeiro, N. M. (2008). Metodologia analítica para quantificar o teor de biodiesel na mistura biodiesel: diesel utilizando espectroscopia na região do infravermelho. Química Nova. 31(2), 421-426. http://dx.doi.org/10.1590/S0100-40422008000200041

Gil, A. C. (2008). Métodos e técnicas de pesquisa social. Atlas.

Holanda, A. (2004). Biodiesel e Inclusão Social. Brasília: Câmara dos Deputados, Coordenação de Publicações.

Jasper, S. P., Biaggioni, M. A. M., Silva, P. R. A., Seki, A. S. \& Bueno, O. C. (2010). Análise energética da cultura do Crambe (Crambe abyssinica hochst) produzida em plantio direto. Engenharia Agrícola. 30, 395-403. http://dx.doi.org/10.1590/S0100-69162010000300004.

Knights, S. E. (2002). Crambe: A North Dakota Case Study, 25 p.

Knothe, G., Gerpen, J. V., Krahl, J. \& Ramos, L. P. (2006). Manual de biodiesel. Edgard Blucher.

Lazzeri, L. \& De Mattei, F. (1997). CRAMBE OIL - A potencial new hidraulic oil and quenchant. Industrial Lubrication and Tribology. 49(2), 71-77.

Le Prestre, P. (2000). Ecopolítica Internacional. Trad. Jacob Gorender. Editora Senac São Paulo.

Lovelock, J. (2009). Gaia: Alerta Final. Editora Intrínseca Ltda., 264p.

Malavolta, E. (1980). Elementos de nutrição mineral de plantas. Agronômica Ceres. 251 p.

Mazzuoli, V. O. (2004). A proteção internacional dos direitos humanos e o direito internacional do meio ambiente. Revista de Direito Ambiental, São Paulo. 9(34), 97-123. http://seer.uenp.edu.br/index.php/argumenta/article/view/117/117

MMA. Ministério do Meio Ambiente, dos Recursos Hídricos e da Amazônia Legal. Meio Ambiente (2017). Acordos globais. MMA, 2012. http://www.brasil.gov.br/meio-ambiente/2012/01/acordos-globais.

MME. Ministério de Minas e Energia. (2008). Comunicação Institucional do Abastecimento da Petrobras Newsday Consultoria de Comunicação e Marketing. Biocombustíveis: 50 perguntas e respostas sobre este novo mercado. $46 \mathrm{p}$.

MME. Ministério de Minas e Energia. (2017). Economia e emprego percentual obrigatório de biodiesel no óleo diesel passa para 8\%. MME.

MME. Ministério de Minas e Energia. (2017). Resenha Energética Brasileira. Colaboração Empresa de Pesquisa Energética. MME: EPE.

Moers, E. M., Kuhn, O. J., Gonçalves Jr., A. C., Franzener, G. \& Stangarlin, J.R. (2012). Levantamento de doenças na cultura do Hochst) na região oeste do Paraná. Scientia Agraria Paranaenis, 11(1), 35-48. http://e-revista.unioeste.br/index.php/scientiaagraria/article/view/5664

Neves, M. B., Trzeciak, M. B., Vinhotes, P. S., Tillmann, C. A. C. \& Villela, F. A. (2007). Qualidade fisiológica em cultura de Crambe produzidas em Mato Grosso do Sul. EMBRAPA. http://www.cpact.embrapa.br/publicacoes/download/livro/Agroenergia_2007/Agroener/trabahos/Outras\%2 0culturas.../Neves_1.pdf.

No, S. (2011). Inedible vegetable oils and their derivatives for alternative diesel fuels in CI engines: A review. Renewable and Sustainable Energy Reviews, 15 , p.131-149. https://doi.org/10.1016/j.rser.2010.08.012

Nobile, F. O. (2009). Uso de resíduos na agricultura. Revista Uniara. 12(2), 1-7. https://revistarebram.com/index.php/revistauniara/ar ticle/view/166\#: :text =A\%20utiliza\%C3\%A7\%C3\%A3o\%20agron\%C3\%B4mica\%20de\%20res\%C3\%ADduos,suced\%C3\%A2neos\%20de\%20mat\%C3\%A9ria\%2Dprima\%20par a

Oliva, A. C. E. (2010). Qualidade de sementes de Crambe submetidas a métodos de secagem e períodos de armazenamento. Dissertação (Mestrado em Agronomia) - Faculdade de Ciências Agronômicas da UNESP, Botucatu.

Oliveira, A. (2011). Regimes Internacionais e a Interação entre a OMC e os Acordos Ambientais Multilaterais, Universidade Federal de Santa Catarina. https://repositorio.ufsc.br/bitstream/handle/123456789/95020/294694.pdf?sequence=1.

Oliveira, S. L. (2002). Tratado de Metodologia Científica: projetos de pesquisas, TGI, TCC, monografia, dissertações e teses. (2a ed.), Pioneira Thomson.

Oplinger, E. S, Oelke, E. A, Kaminski, A. R, Putnam, D. H., Teynor, T. M., Doll, J. D., Kelling, K. A., Durgan, B. R. \& Noetzel, D. M. (1991). Crambe: alternative field crops manual. Department of Agronomy and Soil Science, College of Biological Sciences and Extension agricultural cooperative. Universityof Wisconsin - Madison

Pereira A.S. \& et al. (2018). Metodologia da pesquisa científica. UFSM. https://repositorio.ufsm.br/bitstream/handle/1/15824/Lic_Computacao_MetodologiaPesquisa-Cientifica.pdf?sequence=1

Petrobras Biocombustíveis. (2018). http://www.petrobras.com.br/pt/energia-e-tecnologia/fontes-deenergia/biocombustiveis/.

Pilau, F. G., Battisti, R., Somavilla, L. \& Schwerz, L. (2011). Temperatura basal, duração do ciclo e constante térmica para a cultura do Crambe Agrometeorologia. . Bragantia, 70(4), 958-964. https://www.redalyc.org/articulo.oa?id=90821058032

Pitol, C., Broch, D. L. \& Roscoe, R. (2010). Tecnologia e produção: Crambe. Fundação MS, 2010. 60 p.

Pla, J. A. (2003). Histórico do Biodiesel e suas Perspectivas. http//www.biodiesel.gov..br. 
Research, Society and Development, v. 10, n. 5, e11510514618, 2021

(CC BY 4.0) | ISSN 2525-3409 | DOI: http://dx.doi.org/10.33448/rsd-v10i5.14618

Ramage, J. (1997), Guia da Energia. Monitor.

Regitano-D’arce, M. (2008). Grãos e óleos vegetais - matérias primas. Ciência e tecnologia de alimentos. 7(1), 1-14.

Rosa Junior, E. J., Martins, R. M. G., Rosa, Y. B. C. J. \& Cremon, C. (2007). Calcário e gesso como condicionantes físico e químico de um solo de cerrado sob três sistemas de manejo. Pesquisa Agropecuária Tropical, 36(1), 37-44.

Roscoe, R. \& Delmontes, A. M. A. (2008). Crambe é nova opção para biodiesel. Agrianual 2009. Instituto FNP. 40-41.

Roscoe, R., Broch, D. L. \& Nery, W. S. L. (2010). Análise de Sensibilidade dos Modelos Agrícolas e Industrial de Utilização do Óleo de Crambe na Cadeia Produtiva de Biodiesel em Mato Grosso do Sul. IV Congresso Brasileiro de Mamona e I Simpósio Internacional de Oleaginosas Energéticas. https://ainfo.cnptia.embrapa.br/digital/bitstream/item/18347/1/ECP-12.pdf

Roscoe, R., Richetti, A. \& Maranho, E. (2007). Análise de viabilidade técnica de oleaginosas para produção de biodiesel em Mato Grosso do Sul. Revista de Política Agrícola. 16, 48-59. https://seer.sede.embrapa.br/index.php/RPA/article/view/446/pdf

Soratto, R. P. et al. (2013). Effect of fertilization at sowing on nutrition and yield of Crambe in second season. Revista Brasileira de Ciência do solo. 37(3), 658-666. http://dx.doi.org/10.1590/S0100-06832013000300012

Souza, A. D. V., Fávaro, S. P., Ítavo, L. C. V. \& Roscoe, R. (2009). Caracterização química de sementes e tortas de pinhão-manso, nabo-forrageiro e Crambe. Pesq. Agropec. Bras. 44, 1328-1335. http://dx.10.1590/S0100-204X2009001000017

Souza, C. B. A. de, Sampaio, C. de G., Vasconcelos, A. K. P., \& Barroso, M. C. da S. (2020). Biodiesel as a background theme for graduate students in chemistry: a brief review in the New Chemical Journal. Research, Society and Development, 9(11), e1959119494. https://doi.org/10.33448/rsd-v9i11.9494

Tandy, D. C. (1991). Oil seed extraction. In: WAN, P. J. Introduction to fats and oils technology. Champaign, Illinois: American Il Chemists' Society.

Toebe, M., Brumi, B., Lopes, S. J., Cargnelutti Filho, A. \& Silveira, T. R. (2010). Estimativa da área foliar de Crambe abyssinica por discos foliares e por fotos digitais. Ciência Rural. 40, 475-478. http://dx.doi.org/10.1590/S0103-84782010000200036.

Torres, N.B.D., Chaves, G. de L. D. e Freitas, R.R. de. (2019). Uma revisão bibliográfica de sistemas de avaliação de biodiesel: uma revisão bibliométrica. Pesquisa, Sociedade e Desenvolvimento, 8 (2), e182522. https://doi.org/10.33448/rsd-v8i2.522

Vieites, R. G. (2010). Agricultura sustentável: uma alternativa ao modelo convencional. Revista Geografia, 5(2), 01-12.

Wazilewski, W. T., et al. (2012). Avaliação de Propriedades Físico-químicas do Biodiesel Metílico de Óleo de Crambe abyssinica hochst. Jornal of Agronomic Science. 1(1), 187-195. https://www.researchgate.net/publication/281359492_Avaliacao_de_propriedades_fisico-quimicas_do_bio diesel_metilico_de_oleo_de_Crambe_abyssinica_Hochst/link/5947dccf458515acea121b8b/download 